Meta

Journal des traducteurs

Translators' Journal

\title{
Is Translation Symmetric?
}

\section{Louis Des Tombe}

Volume 37, numéro 4, décembre 1992

Études et recherches en traductique / Studies and Researches in Machine Translation

URI : https://id.erudit.org/iderudit/004494ar

DOI : https://doi.org/10.7202/004494ar

Aller au sommaire du numéro

\section{Éditeur(s)}

Les Presses de l'Université de Montréal

ISSN

0026-0452 (imprimé)

1492-1421 (numérique)

Découvrir la revue

\section{Citer cet article}

Des Tombe, L. (1992). Is Translation Symmetric? Meta, 37(4), 791-801.

https://doi.org/10.7202/004494ar

\section{Résumé de l'article}

Les propriétés générales de la relation de traduction présentent un intérêt pour les traducteurs, les traductologues et les concepteurs de systèmes de traduction automatique. Puisque la traduction est d'une certaine façon liée à la notion intuitive d' " équivalence ", on peut se demander si elle possède les propriétés de l'équivalence mathématique stricte. La symétrie est l'une de ces propriétés. L'article débute par quelques définitions pour que la question posée puisse prendre sens. La réponse se révèle positive pour la traduction " parfaite ", mais négative pour la traduction " imparfaite "; cela, à cause d'une tendance de la part des traducteurs à « affaiblir » les assertions faites dans les textes. Cet aspect asymétrique de la traduction imparfaite est expliqué en le reliant à une vue " monotonique " de l'organisation du discours. L'article se termine par une description d'un système de traduction automatique conçu pour produire des traductions parfaites, et en tire des conclusions pour la conception de systèmes de traduction automatique.
Ce document est protégé par la loi sur le droit d'auteur. L’utilisation des services d’Érudit (y compris la reproduction) est assujettie à sa politique d'utilisation que vous pouvez consulter en ligne.

https://apropos.erudit.org/fr/usagers/politique-dutilisation/ 


\title{
IS TRANSLATION SYMMETRIC?
}

\author{
LOUIS DES TOMBE \\ Research Institute for Language and Speech, Utrecht, Netherlands
}

\begin{abstract}
Résumé
Les propriétés générales de la relation de traduction présentent un intérêt pour les traducteurs, les traductologues et les concepteurs de systèmes de traduction automatique. Puisque la traduction est d'une certaine façon liée à la notion intuitive d' "équivalence», on peut se demander si elle possède les propriétés de l'équivalence mathématique stricte. La symétrie est l'une de ces propriétés. L'article débute par quelques définitions pour que la question posée puisse prendre sens. La réponse se révèle positive pour la traduction "parfaite», mais négative pour la traduction «imparfaite»; cela, à cause d' une tendance de la part des traducteurs à "affaiblir" les assertions faites dans les textes. Cet aspect asymétrique de la traduction imparfaite est expliqué en le reliant à une vue «monotonique» de l'organisation du discours. L'article se termine par une description d'un système de traduction automatique conçu pour produire des traductions parfaites, et en tire des conclusions pour la conception de systèmes de traduction automatique.
\end{abstract}

\begin{abstract}
General properties of the translation relation are of interest to translators, translatologists and machine translation system designers. As translation is somehow related to the intuitive notion "equivalence", one wonders whether it has the properties of strict mathematical equivalence. Symmetry is one of these. The paper starts out with some definitions, so that the question can be treated in a meaningful way. The answer turns out to be positive for "perfect" but negative for "imperfect" translation; the latter because of a tendency of translators to "weaken" claims made in texts. This asymmetric aspect of imperfect translation is explained by relating it to a "monotonic" view of the organization of discourse. The paper ends with a description of a machine translation system designed to produce perfect translation, and draws conclusions about machine translation design.
\end{abstract}

\section{INTRODUCTION}

Communication between students of translation and those of machine translation has always been limited. Perhaps this is caused by the fact that the practical questions of the two fields are very different, together with a certain neglect of theoretical questions that the two fields might share. In this paper, I would like to examine symmetry of translation as an example of a kind of theoretical question that is of interest to both cultures.

For the moment, let "symmetry of translation" be defined very loosely as follows. Suppose that text $s$ gets translated as text $s^{\prime}$, and that we somehow conclude that this translation has a certain quality, say "goodness N". Would the translation from $s$ ' to $s$ also have goodness $\mathrm{N}$ ? We can say that translation is symmetric if for all $s$ and $s^{\prime}$, goodness is the same independently of the direction of the translation. ${ }^{2}$

It should be clear that this paper is about symmetry of translation only with respect to the quality of the translation, i.e., the question whether $\left(s, s^{\prime}\right)$ is as good as $\left(s^{\prime}, s\right)$. I will not touch on related matters of interest such as:

symmetry with respect to probability of occurrence: for all $s$ and $s^{\prime}$, if $s$ translates as $s$ ' with probability $\mathrm{P}$, then $s^{\prime}$ translates as $s$ with probability $\mathrm{P}$; 
symmetry with respect to underlying processes: for all $s$ and $s^{\prime}$, if the translation from $s$ to $s^{\prime}$ is achieved by the use of some set of processes C, then so is the translation from $s$ ' to $s$ (where we may situate $\mathrm{C}$ in the translator's head or in the computer).

Symmetry with respect to quality does not necessarily imply the other two kinds of symmetry, though this depends in part on what we want quality to be. For symmetry with respect to probability, this is easy to see from an example. Suppose language $L$ has two words $w 1$ and $w 2$ that are exact synonyms (with respect to properties important to preserve in translation such as meaning, style, register) and occur in $L I$ with non-zero probabilities. Let the word $w O$ in language $L O$ be the translation of both $w 1$ and $w 2$; but $L O$ has only one word with this meaning. So, (almost) always, $w 1$ and $w 2$ get translated as $w 0$, and $w 0$ either as $w 1$ or as $w 2$. It is clear that the probability of the translation $w 1 \rightarrow w 0$ is higher than the probability of the translation $w 0 \rightarrow w 1$, though for many applications the quality of the two translations can be considered the same.

With respect to translation processes, it is clear that from symmetry of the translation relation, it does not necessarily follow that the processes computing this relation must be the same in both directions, though of course if translation quality is symmetric, there are some possibilities for a design for a computer program that makes use of this fact.

The question whether translation is symmetric with respect to quality is of interest to anybody involved in translation.

To the practical translator, it is important to understand better what (s)he is trying to do. It is often said that translation is somehow "equivalence", but this is not always defined very clearly. One possible interpretation is that $s$ and $s$ ' "have something in common"; having something in common is symmetric. But intuitively, translation quality is not always symmetric. So there may be a problem here, concerning the definition of equivalence.

It needs no discussion that to the translation theorist, the notion "equivalent" is of crucial importance.

To the designer of a machine translation system, it is essential to understand some formal properties of what the machine is supposed to do. If the task of the program is to define a symmetric relation, then this influences in various ways how the program will be put together. Given the fact that big grammars and dictionaries are involved, assumptions like symmetry are potentially useful in that they may reduce the conceptual complexity of the program - one of the major stumbling blocks in natural language processing. Moreover, a symmetric relation, if implemented in the form of a reversible program, enables the grammar writer to do very useful cross-checking during development.

The rest of this paper is organized in 4 sections. Section 2. is about the goal of translation and about what it means for a translation to satisfy its goal. Section 3. looks at properties of "perfect" translation, i.e. translation that satisfies its goal, showing amongst other things that it is symmetric. Section 4. examines whether imperfect translation is symmetric; here the conclusion is negative. Section 5. is about the relevance of the discussion for machine translation.

Throughout the paper, I use the words "author" and "reader" of a text to include respectively "speaker" and "hearer" in the traditional linguistic sense.

\section{TRANSLATION GOALS}

What does a translator try to achieve? It is not clear whether there is one standard answer to this question. Typical answers have been given in terms of "preservation of linguistic properties" or "preservation of the effect on the reader" (e.g. Catford (1965), Newmark (1988), Nida and Taber (1969), Landsberg (1976)). "Equivalent effect" seems to represent today's majority opinion. In this paper, I will follow this idea. 
Given some particular text $s$ read by some individual reader $r$, there is some total "effect". I will write this as $E(r, s)$ : the effect on reader $r$ of text $s$.

It is not clear what $E(r, s)$ actually is. In principle, $r$ changes somewhat by reading $\mathrm{s}$, e.g. $r$ has understood the meaning of $s, r$ has understood the communicative intention of the author of $s, r$ will behave in a different way in the future. In this paper, I will try to make only minimal assumptions about the nature of $E(r, s)$. One necessary assumption is that the ideal translator always knows whether two texts (source and target) have the same effects on their respective readers. Of course, the actual translator will make mistakes, but that is not the concern of this paper.

Most of the time, an author, and therefore also a translator, is not concerned with the effect of some text on one individual reader, but with the effect on a class of readers. I will use capital $R$ to refer to the idealized reader representing such a class.

So far, the result is that the translator's task must be relativized with respect to two classes of readers. This is unsurprising to most translators, I suppose; but still worth making explicit. Consequently, we have the following first definition of the translator's task:

(1) Given a text $s$, a representative idealized reader $R$, and a representative intended reader $R^{\prime}$ of the translation, find $s^{\prime}$ such that $E(R, s)=E\left(R^{\prime}, s^{\prime}\right)$

(1) says that the translator's task is to be defined in terms of a given text and two reader classes. As assumed above, the ideal translator always knows whether the condition is fulfilled. Note that any two classes of readers will fit the definition; usually, what is called "translation" refers to the case where $R$ and $R$ ' differ at least in that they understand two different languages.

The definition is simplistic in one respect: it says that the complete effect has to be preserved. I think that this is not a well-chosen ambition for translation. Often, only a part of the effect is relevant. Two examples may illustrate this.

First, compare the following two translation tasks.

(2) In a newspaper, a "literal" translation is given of a speech by Boris Yeltsin to the Russian parliament to show what he said "in his own words".

(3) The translation of a computer manual.

In case (3), the way in which the original manual was written is irrelevant. The only thing that counts is whether the user will be able to use the computer. Various elements like voltage, addresses of maintenance companies, examples of use, may be adapted to the user's situation. On the contrary, in case (2), such adaptations are out of the question, as the idea is to show to the target language readers how Yeltsin said what he said.

Second, look at the following discussion by Newmark:

“...Spears' (1966) translation of the following passages of De Gaulle's 18 June 1940 broadcast is unacceptable: (...)

- 'Car la France n' est pas seule! Elle n' est pas seule! Elle n'est pas seule!'

- 'For remember this, France does not stand alone. She is not isolated.'

- (Suggested version: 'For France is not alone! She is not alone! She is not alone!')

In these and other passages, Spears has attempted to modify the starkness, simplicity and rawness of De Gaulle's speech..." (Newmark 1988: 44-45).

I find this an intriguing little discussion. One interpretation of it is that Spears simply overlooked the alternative version mentioned by Newmark. An alternative possibility is that Spears did consider the alternative, but that he did not find his own translation unacceptable, because he simply did not intend to maintain the emotional parts of the 
effect. The latter seems somewhat more plausible because the more literal translation is easy to find.

I conclude that translation tasks are defined with respect to certain translation goals, which are definitions of what properties of $E(R, s)$ should be present in $E\left(R^{\prime}, s^{\prime}\right)$. Distinctions of such types have been made in the literature, such as Newmark's own distinction between "semantic" and "communicative" translation, House's distinction between "overt" and "covert" translation, and others. See Newmark (1991: 13) for an overview, and also Gutt (1990) for interesting discussion.

In order to accommodate the idea of translation goals, it has to be assumed that $E(R, s)$ is somehow structured. I will assume that it can be analyzed in terms of component effects, and that each component is of some value on some "dimension" or, as I will call it, some "attribute". ${ }^{3}$ The value of any attribute may itself be complex. For example, suppose there is an attribute "understanding the meaning of $s$ ". For some $E(r, s)$, the value of this attribute is the actual meaning of $s$ as understood by $r$. This value may itself be complex: it may be organized in terms of further attributes like the understanding of the logical meaning, of the style, of the degree of politeness, of the way in which the text is syntactically composed, etc., and also the "perceptual complexity" of the understanding process itself.

To my knowledge, House (1981) is the earliest source that uses an organization in terms of attributes and values as a basis for translation quality evaluation. Some further thoughts on the structure of $E(r, s)$ with a view on translation are in Dings (1991); for example, one may find some attribute more "important" than some other. However, in this paper I will not be concerned any further with the internal structure of $E(r, s)$, but only use the idea that it is a set of attributes with (possibly complex) values.

Given the idea that $E(R, s)$ is a set of attribute-value pairs, a translation goal can be defined as a set $Q: Q$ is the set of attributes whose values the translator tries to preserve. For example, Newmark defines his semantic and communicative translation as follows:

"Communicative translation attempts to produce on its readers an effect as close as possible to that obtained on the readers of the original. Semantic translation attempts to render, as closely as the semantic and syntactic structures of the second language allow, the exact contextual meaning of the original" (Newmark 1988: 39).

Communicative translation in Newmark's definition says that $Q$ equals all attributes of effects (i.e. the total effect); semantic translation says that $Q$ contains only the attribute "contextual meaning".

Given translation goals, we get the following final version of a translator's task:

(4) Given a text $s$, a representative idealized reader $R$, a representative intended reader $R^{\prime}$ of the translation, and a translation goal Q, find $s^{\prime}$ such that $E(R, s)$ and $E\left(R^{\prime}, s^{\prime}\right)$ have the same values for all attributes in $Q .{ }^{4}$

This may or may not be a surprising result, but it is certainly not uncontroversial. Here are two quotations from articles in past Meta issues that oppose it:

"The aim of translation is to reproduce in the TL, as faithfully as possible (i.e. at all levels: morphological, phonological, syntactic, lexical, semantic — and even stylistic), all the linguistic features of which the SL is composed" (Landsberg 1976: 235).

"... for the translator, the only type of translation that counts is 'total translation'..." (Henry 1984: 152).

It should be obvious that I disagree strongly with both. 


\section{PERFECT TRANSLATION AND EQUIVALENCE}

The question whether translation quality is symmetric presupposes that we see translation somehow as a relation; it must first be made clear what the terms of this relation are. The most natural definition is, in my view, that a translation is a pair of pairs:

(5) $\left((R, s),\left(R^{\prime}, s^{\prime}\right)\right)$

In this way the relativization to reader classes is built into the definition of the translation relation itself.

Moreover, as indicated in the introduction, we need evaluative categories, i.e. values that "goodness" can take. Given the conclusions in the preceding section, goodness must be relativized with respect to the translation goal Q. As a starting point, consider only two possible goodness values for translation: perfect $_{Q}$ and imperfect $Q$, loosely defined as follows:

The quality of a translation $\left((R, s),\left(R^{\prime}, s^{\prime}\right)\right)$ will be said to be perfect $_{Q}$ if, for all attributes in $Q, E(R, s)=E\left(R^{\prime}, s^{\prime}\right)$; and imperfect $Q$ in all other cases.

Given this, it can easily be seen that perfect $Q$ translation is symmetric: for any $Q$, $\left((R, s),\left(R^{\prime}, s^{\prime}\right)\right)$ is perfect $Q$ if and only if $\left(\left(R^{\prime}, s^{\prime}\right),(R, s)\right)$ is perfect ${ }_{Q}$. In fact, perfect ${ }_{Q}$ translation (for any $Q$ ) is an equivalence relation in the mathematical sense. ${ }^{5}$

\section{IMPERFECTION AND ASYMMETRY}

Many translations that are actually produced are not perfect. Though this may sometimes be caused by mistakes on the part of the translator, often the reason why an imperfect translation is produced is that a perfect one simply does not exist. It is useful, though, to look at the situation in terms of the quality criterion $Q$.

A well-known translation problem type is "lexical mismatches" across languages. Take French cousine vs English cousin. The information content of the two words is not the same; so, if $Q=\{$ information_content $\}$, the translation pair:

(6) ((French-readers, cousine),(English-readers, cousin))

is imperfect. However, for this $Q$ there is a perfect pair:

(7) ((French-readers, cousine),(English-readers, female cousin))

But translating cousine systematically as female cousin may, in many contexts, cause special pragmatic or stylistic effects on the English readers that are not present in the French case. Suppose now that $Q$ contains not only information content but also, say, "naturalness of expression". In that case (7) is not perfect either, because (at least in some cases) the English text sounds less natural to the English reader than the French text to the French reader.

So, under certain translation goals, some translation tasks simply do not have perfect solutions. In the example, if $Q=\{$ information_content, naturalness $\}$ then (6) is imperfect because of the information content and (7) because of naturalness.

One may wonder whether perfect translations exist at all. I tend to take an optimistic view here: if $R$ and $R^{\prime}$ are sufficiently similar with respect to their knowledge and attitudes, and with a relatively restricted translation goal, there seems not to be a very strong reason why perfection would be impractical. For example, perfect translation of technical medical articles, where both $R$ and $R^{\prime}$ are doctors and $Q$ consists of only, say, illocutionary force and information content, should often be possible. 
Nevertheless, Toury (1980) is quite right in pointing out that the dichotomy perfect/imperfect is not yet very illuminating as a way to evaluate translation. A really interesting translation theory should say something about the quality of imperfect translation.

In what follows I would like to present one way of looking at certain translations as being imperfect but still rather good, and examine whether such translations are symmetric.

The starting point is that a pair like (6) is, though imperfect with respect to information content, better than a totally arbitrary pair like (8):

(8) ((French-readers, cousine),(English-readers, baby))

This suggests two ideas.

First, perhaps the best way to look at imperfect translation is not in terms of absolute "goodness" evaluations, but in terms of relative, "better than" evaluations. It is quite hard to say in absolute terms how good (6) is, even if it has to be judged only in terms of information content. But everybody would agree that (6) is better than (8). One may set up the theory of quality of imperfect translation in terms of general rules specifying what kinds of imperfect translations are better than what other kinds.

Second, the comparison (6)-(8) suggests one such general rule. It may be tentatively formulated as:

(9) Strengthening/weakening:

with respect to the attribute information content, an imperfect pair $\left((R, s),\left(R^{\prime}, s^{\prime}\right)\right)$ is better than an imperfect pair $\left((R, s),\left(R^{\prime}, t^{\prime}\right)\right)$, if $(R, s)$ and $\left(R^{\prime}, s^{\prime}\right)$ are a strengthening / wcakcning pair and $(R, s)$ and $\left(R^{\prime}, t^{\prime}\right)$ are not, where:

(10) A strengthening/weakening pair is a pair $(x, y)$ such that either $x \rightarrow y$ or $y \rightarrow x$ but not both.

Of course, (10) sounds vague, but that can easily be remedied if information content is seen in a logical perspective, where stronger information implies weaker information. I prefer to stay on an intuitive level here - it should be enough that (French, cousine) is stronger than (English, cousin). This relation does not exist between cousine and baby. Between these, there is simply the relation of overlap: some cousines are babies, and some babies are cousines. Overlap is not a very interesting basis for translation, but strengthening/weakening is; and in practice it is used often by translators.

One possible way to see imperfect translation is to compare it to the intuitive notion of "similarity" or, in another word, "closeness". The smaller the "distance", the better the translation. This idea can explain that, often "something gets lost" in a translation. Closeness is not an equivalence relation in the mathematical sense: it is not transitive. If $\mathrm{A}$ is close to $B$ and $B$ is close to $C$, it does not follow that $A$ is close to $C$. However, it is symmetric: if $\mathrm{A}$ is close to $\mathrm{B}$, then $\mathrm{B}$ is close to $\mathrm{A}$. The distance is the same, irrespective of the direction.

I will now show that this view is not right, at least not always: in some cases, imperfect translation is not symmetric. Consider the next (realistic) example:

(11) French ... réalise un chiffre d'affaires annuel d'environ 100 millions de marks English ... logs annual sales of just under DM 100 million (Italics mine)

The pair environ/just under is a case of strengthening/weakening: just under implies environ, but not vice versa. I asked some translators and linguists what they thought about the translation, sometimes pretending that (11 French) was the source text, and sometimes that (11 English) was. It was not difficult to establish that most of these people would only in special circumstances translate from (11 French) to (11 English). 
The reason given by most judges is that a translator would not translate environ as just under. In other words, the quality of (11 French) $\rightarrow$ (11 English) is less good than the quality of its opposite. It follows that this is a case of asymmetric translation quality. From just under to environ is better than from environ to just under, so the two pairs do not have the same "goodness".

Therefore, in addition to (9) we should have (12):

(12) Weakening:

with respect to information content, an imperfect pair $\left((R, s),\left(R^{\prime}, s^{\prime}\right)\right)$ is better than an imperfect pair $\left((R, s),\left(R^{\prime}, t^{\prime}\right)\right)$ if $\left(R^{\prime}, s^{\prime}\right)$ is weaker than $(R, s)$ and $\left(R^{\prime}, t^{\prime}\right)$ is not.

Weakening translation has been mentioned in some translation studies but a systematic study of it is absent. In literary translation, strengthening has been found (van Leuven-Zwart 1990) as well as weakening (J. Hulst, private communication). Maybe in literary translation the importance of logical meaning as compared to other attributes is lower than in nonliterary translation - I have no good view to offer here. But for translation where the logical meaning is an attribute of primary importance, weakening seems to be what many translators expect.

One has to wonder what principle underlies rule (12). It is surprising in a sense because just under is just as different in meaning from environ as environ is from just under.

Suppose we see texts as information providers: as the text moves on, more and more information is added. Usually, the claim expressed will become stronger; it will never become weaker, unless the text is inconsistent. But the final information in the head of the reader does not come from the text only: the reader supplies information himself as well. ${ }^{6}$ So, the final information state can be seen as the conjunction of all the information in the text with all the information supplied by the reader.

Given this picture of what a text does, it can be seen why weakening is preferred over strengthening. In the case of weakening, it remains possible that information provided by $R^{\prime}$ (the target text reader) or whatever other source will be added to what the target text $s^{\prime}$ provides, thereby making the final information state of $R^{\prime}$ more similar to that of $R$ after reading the source text $s$. On the other hand, if one translates by strengthening, no additional information can make its effect undone and still be consistent with the infor. mation in $s$ '. The translator's principle can be summarized as never provide more information in $s^{\prime}$ than is provided in $s$. This causes asymmetric judgments of translation quality.

This hypothesis has some empirical consequences.

One application of it is that sometimes a "local weakening" is undone by information later in the text itself. Example:

$\begin{array}{lll}\text { (13) French: } & \text { Ma cousine est entrée. } & \text { Elle riait } \\ \text { English: } & \mathrm{My} \text { cousin came in. } & \text { She laughed }\end{array}$

Translation (13) as a whole is not a case of weakening, but a case of perfect translation (with respect to information content); its special feature is that the information is distributed over the words differently in the two texts: only the pronoun restricts the cousin to a female person. I would call this a case of "natural compensation".?

A more interesting consequence of the hypothesis above is the following. In some constructions, certain elements are as it were "closed" for additional information. Such elements are not even candidates for "compensation" like example (13); but the theory so far predicts also that, since no further information can be added about them, weakening should not work for them. In fact, this seems to be the case, as can be seen in the following two examples. 
Example 1: indefinite noun phrase under the scope of negation.

(14) John does not have a cousin.

No additional information can be given about the cousin, as shown in (15).

(15) *John does not have a cousin $i$. She $i$ is blond.

Translation by weakening is intuitively much less good than in the examples above $(6,11)$, as shown in $(16)$ :

(16) English John does not have a cousin

French Jean n'a pas de cousine

Note that in (16), the direction of the weakening is inverted: the statement expressed by the English text is stronger than the one expressed in French. ${ }^{8}$ That is, English-toFrench should be relatively acceptable, and French-to-English less so. It is my personal intuition that (16) is equally bad in both directions, but certainly nobody would find the English-to-French translation better than the French-to-English translation. ${ }^{9}$

Example 2: Indefinite noun phrase in if-then constructions:

(17) If a cousin of the queen laughs, then John is happy.

The same results obtain. First, no further information can be given about the cousin (18):

(18) *If a cousin $i$ of the queen laughs, then John is happy. She $i$ is blond.

And again translation by weakening sounds very bad, as shown in (19); note that the weakening translation is the translation from English to French - the French text says nothing about what happens if a male cousin of the queen laughs.

(19) English: If a cousin of the queen laughs, then John is happy

French: $\quad$ Si une cousine de la reine rit, Jean est heureux

Again, some judges even prefer the strengthening translation, but certainly nobody prefers the one obtained by weakening.

The elements that I have called "closed for additional information" are, in fact, the same that are called "inaccessible for anaphoric reference" in discourse representation theory (Kamp 1981), which is based on the idea of adding more and more information that I loosely described above. The data imply at least that weakening must be restricted somehow; but the parallellism with the "inaccessibility" cases suggests that the explanation given is correct.

The idea of weakening can be refined and extended in many ways. For example, one may introduce degrees of weakening, where e.g. cousine could be weakened progressively to English cousin and relative, in the spirit of modern lexical semantics (e.g. Pustejovski and Bergler (1991)). One may wonder whether something similar to weakening applies to other attributes of the effect on the reader, such as politeness, illocutionary force, style ("flattening"). And one may look at texts that are not informative texts in the first place; perhaps, information content is not an element of $Q$ for such texts, or the elements in $Q$ are somehow ranked with respect to their relative importance. I leave these issues for the future. What I hope to have shown here is that one can talk in a systematic way about the quality of imperfect translations. 


\section{TRANSLATION AND MACHINES}

I leave it to the reader to determine whether the preceding discussion has something to say to human translators. But I will make a few comments on its relevance to machine translation (MT).

The large majority of current MT systems is based on the "post-editing paradigm": the machine produces imperfect translations and the human post-editor corrects them. Practical evaluation is in terms of the global cost-effectiveness of the man-machine combination, compared to purely human translation.

Many MT designers feel some discomfort because this paradigm makes it difficult to describe the quality of the MT system itself. Perhaps for the end user, that is not a problem; but for the system developer, it would be a good thing to have some more refined picture of what the system is supposed to achieve.

Moreover, the post-editing paradigm is not helpful to users who know only one of the two languages. For example, if you are not a Dutch speaker and you would like to write a letter in Dutch, you would probably not use a machine based on this paradigm, since you cannot do the post-editing.

Therefore, a different course of action for MT would be to look at system design from the perspective of some systematic theory of translation quality. This is rare in MT but not entirely absent. The design of the Rosetta ${ }^{10}$ system was based on, amongst other things, certain views on translation. With respect to translation quality, this system can be characterized as follows: ${ }^{11}$

- $Q$ contains two attributes:

- linguistic information content,

- meaning composition.

- The system produces only perfect translations.

By "linguistic information content", I mean the information content as far as the reader is forced to understand it by the text only; the contribution of the reader's knowledge of the world is not taken into account (since this problem is considered to be "AI-complete", i.e. it requires full artificial intelligence). Therefore, given a sentence in some maintenance manual like the well-known example check for wear or damage, Rosetta in isolation will produce not only the more plausible translation ${ }^{12}$ but also Op slijtage kontroleren of beschadigen. ${ }^{13}$

In order to be of some practical value, the system is "interactive": whenever it detects ambiguities, like the one just given, that cannot be solved on linguistic grounds but need knowledge of, e.g., plausibility of instructions in maintenance manuals, it asks the user which meaning (s)he intends. The user is supposed to understand the source language but does not have to know the target language - the interaction takes place during the analysis of the source text.

By "meaning composition" I mean the following. Rosetta is based on the kind of linguistic theory that says that linguistic expressions are built by some recursive process from linguistic expressions (down to basic expressions: say, words), and that the meaning of the whole expression is built by some "meaning operation" from the meanings of the parts.

For example, the two expressions in $(20)$ have the same information content ${ }^{14}$ but not the same meaning composition:

(20) a. every student is intelligent

b. there are no unintelligent students 
Rosetta produces only perfect translations (with respect to its Q) because it is designed as follows: the basic meanings and the meaning operations are assumed to be common to the 3 languages treated; their syntactic realizations, however, are (of course) language-specific. Therefore, each time the system can analyse a source text as built recursively in a certain way, it also knows how its meaning is composed; and therefore, it knows how to build a translation. But it does not know that (20a) and (20b) are logically equivalent. So, for a given source text, it will not always produce all the perfect translations. ${ }^{15}$ It should be clear that Rosetta-translation is symmetric.

Such a translation system does not have the problems of the post-editing paradigm:

- what it tries to achieve is quite clear, so the grammar writers and lexicographers have a better basis for decisions;

- the monolingual user can be reasonably sure that what the system produces is correct - it is designed to guarantee this, though of course, errors in its grammars and dictionaries are not excluded by the design.

Rosetta runs into problems with respect to imperfect translation. E.g. given lexical translation problems, there is no perfect translation with respect to Rosetta's translation goal. The Rosetta linguist is forced to either pretend that cousin/cousine is a perfect translation or relate cousine to something like female cousin (in which case meaning composition is not preserved). The present rescarch is relevant for a quality-driven approach to machine translation in that it attempts to come to grips with issues like this. It is obvious that a view like the one taken here has implications for MT design. For example, an interlingual design would be excluded: since the meaning can change, it is not clear what the interlingual expressions would represent. Another consequence is that, given the asymmetric nature of imperfect translation, not all parts of a translation system can be reversible.

\section{CONCLUSION}

The main ideas I would like to get across in this paper are the following.

Suppose one finds it important to know what translation quality is. The paper proposes to see this as the degree to which a translation approaches perfection, where perfection means that the source and the target text have the same effects on their respective readers, for certain specified aspects of effects.

Perfect translation is formally clear: it is an equivalence relation in the strict sense, i.e. reflexive, symmetric, and transitive.

A translation task is defined by (i) two kinds of readers, (ii) aspects of the effect that are to be preserved, and (iii) a source text. Unfortunately, it is not the case that for every translation task, there is a perfect solution. Often, the translator has to choose amongst various imperfect solutions.

Imperfect translation is not an equivalence relation in the strict sense. This is why people in general will not believe that translation is transitive: something may "get lost" in translation. The paper proposes that (imperfect) translations can be compared in terms of an ordering relation better than. One can try to formalize this relation by means of generalizations defining preferences for certain translations over others. As an example, a rule is formulated, saying that weakening is relatively good. This rule is explained by reference to certain monotonicity properties of information processing: in the course of reading a text, the reader usually adds information.

If the weakening rule is correct, then imperfect translation is not symmetric with respect to its quality. This follows from the asymmetry of weakening. This rules out some 
possible hypotheses about imperfect translation as "similarity" or "semantic distance", if these are defined as symmetric relations.

Finally, the paper describes some aspects of the Rosetta MT system, showing that certain ideas of translation quality can actually be used in the design of translating computer programs. Rosetta is based on a view that one can describe as "idealistic". The reward for this is an orderly design, on the basis of which a serious coverage can be combined with high quality translation. However, the drawback is that imperfection cannot be dealt with in a systematic way. Some possible design improvements are mentioned.

\section{Notes}

1. I thank Toon Cohen, Crist-Jan Doedens, Jacqueline Hulst, Steven Krauwer, Jan Landsbergen, Graham Russell and Susan Warwick-Armstrong as well as my non-anonymous reviewers Doug Arnold and Dominique Estival for inspiration and useful comments.

2. A more precise definition is given below, in section 3. This article is at an intuitive level. A few somewhat technical remarks are in endnotes, but they can be skipped without problems.

3. I see attributes as functions from effects to (partial) effects.

4. $s^{\prime} /$ q in $Q: q(E(R, s))=q\left(E\left(R^{\prime}, s^{\prime}\right)\right)$.

5. The word "equivalent" is often used in translation theory, but rarely defined. A binary relation is an equivalence relation in the mathematical sense if:

it is reflexive, i.e. $\forall x: x R x$ it is symmetric, i.e. $\forall x, y: x R_{y}$ iff $y R x$

it is transitive, i.e. $\forall x, y, z:$ if $x R y$ and $y R z$ then $x R z$.

6. In fact, this is one of the main reasons why natural language understanding is so difficult for computers.

7. Very brief explanation: a case of natural compensation is a case where, in a natural way and without special tricks, a local weakness in a translation is remedied to some degree by the translation of another part of the text so that the translation as a whole is better than the translations of the parts.

8. If John does not have a cousin, it logically follows that he has no female cousin - but not the other way round.

9. In fact, the French-to-English translation is preferred by some judges; I have no explanation for this tendency.

10. Rosetta was developed by Landsbergen and his colleagues at Philips research in the Netherlands (Landsbergen 1984).

11. This account is a bit simplified in that Rosetta actually does some preservation of syntactic form.

12. Kontroleren op slijtage of beschadiging.

13. This Dutch sentence is not ambiguous in the way the English source sentence is - it means that the reader is instructed to either check the machine for wear or damage it.

14. Some linguists would maintain that (20a) somehow implies that there must exist students, while (20b) does not or less strongly imply this. I do not want to discuss that here; with respect to strictly logical meaning, the two are equivalent.

15. In fact, if indeed (20a) and (20b) are non-equivalent pragmatically, the fact that Rosetta does not intertranslate them is a fortunate accident.

\section{BIBLIOGRAPHY}

CATFORD. J. C. (1965): A Linguistic Theory of Translation, Oxford University Press.

DINGS, J. (1991): "Partial Ordering of Candidate Translations. Some Consequences for the Evaluation of MT Systems", Talk at Evaluators' Forum, Ste Croix, Switzerland, April 1991.

GUTT, E.-A. (1990): Translation and Relevance, Blackwell.

HENRY, R. (1984): "Point for Inquiry into Total Translation: Review of Catford's (1965)", Meta, 29-2, $152-158$.

HOUSE, J. (1981): A Model for Translation Quality Assessment, Narr, Tübingen, Germany.

KAMP, H. (1981): "A Theory of Truth and Discourse Representation", Groenendijk, Jansen, and Stokhoff, (Eds.), Formal Methods in the Study of Language.

LANDSBERG, M. (1976): "Translation Theory: An Appraisal of some General Problems", Meta, 21 -4, $235-251$.

LANDSBERGEN, J. (1984): "Isomorphic Grammars and their Use in the Rosetta Translation System", King (Ed. 1987), 351-372.

NEWMARK, P. (1988): Approaches to Translation, Prentice Hall.

NEWMARK, P. (1991): About Translation, Multilingual Matters, Clevedon, UK.

NIDA, E. A. and C. TABER (1969): The Theory and Practice of Transiation, Brill, Leiden, The Netherlands.

PUSTEJOVSKI, J. and S. BERGLER (1991): "Lexical Semantics and Knowledge Representation", Proc. Workshop SIG Lexicon of the ACL, Berkeley, CA, USA.

TOURY, G. (1980); In Search of a Theory of Translation, Porter Institute, Tel Aviv, Israel.

VAN LEUVEN-ZWART, K. (1990): "Translation and Original: Similarities and Dissimilarities II", Target, 2, 69-95. 